\title{
Rotas funcionais de leitura de palavras isoladas em crianças bilíngues
}

\author{
Functional routes of reading of isolated words in bilingual children
}

Angelo Horst ${ }^{[a]}$, Leandro Kruszielski[b]

\footnotetext{
[a] Psicólogo pela Faculdade Dom Bosco, Curitiba, PR - Brasil, e-mail: angelohorst@gmail.com

${ }^{[b]}$ Psicólogo, doutorando em Educação pela Universidade Federal do Paraná (UFPR), docente da Faculdade Dom Bosco, Departamento de Psicologia, Curitiba, PR - Brasil, e-mail: leandro.psi@gmail.com
}

Recebido: 08/11/2010 Received: $11 / 08 / 2010$

Aprovado: 17/03/2011 Approved: 03/17/2011

\section{Resumo}

O objetivo deste trabalho é analisar as rotas cognitivas de leitura de palavras isoladas preferencialmente utilizadas por alunos bilíngues falantes de português e alemão ou português e inglês do $3^{\circ}, 4^{\circ}$ e $5^{\circ}$ ano do Ensino Fundamental de colégios particulares da cidade de Curitiba. A amostra foi composta por 34 crianças falantes somente do português, sendo 24 crianças do sexo feminino e dez do sexo masculino, e outro grupo de 30 crianças bilíngues, sendo 20 crianças falantes do português e alemão (sete crianças são do sexo masculino e 13 do sexo feminino) e dez crianças falantes de português e inglês (cinco crianças do sexo masculino e cinco do sexo feminino). Ao todo, 64 crianças participaram. De acordo com os resultados, os falantes somente da língua portuguesa utilizam preferencialmente a rota lexical, enquanto os bilíngues utilizam preferencialmente ambas as rotas. Não houve efeito de extensão na leitura dos grupos, sendo que os efeitos de regularidade e frequência foram mais intensos no grupo controle e o efeito de lexicalidade mais intenso no grupo de bilíngues. Mesmo sendo os valores semelhantes, essa diferença foi estatisticamente significativa. Em relação ao desempenho geral, notou-se que o salto qualitativo se deu aos 10 anos, com crianças desta idade tendo escores mais altos e estatisticamente significativos em relação às demais.

Palavras-chave: Leitura. Cognição. Multilinguismo.

\section{Abstract}

The aim of this paper is to analyze the cognitive routes when reading of isolated words used by bilingual speakers - Portuguese and German or Portuguese and English - in the 3rd, 4th and 5th grades of Brazilian elementary education system in private schools in the city of Curitiba. A total of 64 subjects participated in the experiment. They were 34 children that speak only Portuguese (24 female, ten male) and another group of 30 bilingual children: 20 Portuguese) German speakers (seven male, 13 female) and ten Portuguese/English speakers (five male, five female). According to the results, the subjects that were only able to speak Portuguese had a preference for the lexical route, while the bilingual ones preferred both routes. There was no 
length effect in reading groups, and the effects of regularity and frequency were more intense in the control group. The effect of lexicality was more intense in the bilingual group. Even if the values were similar, the difference was statistically significant. Regarding overall performance, the breakthrough occurred in children at 10 years old. Those subjects had a higher and statistically significant scores if compared to others.

Keywords: Reading. Cognition. Multilingualism.

\section{Introdução}

Compreender o ser humano nunca foi e nunca será tarefa fácil. A psicologia, por meio de suas diversas teorias psicológicas sobre a constituição biopsicossocial do homem, muitas vezes se depara com a impossibilidade de ultrapassar a barreira que faz e caracteriza, justamente, o ser humano como ele é: sua complexidade.

A genética, a biologia, a cultura e todas as outras disciplinas se chocam na busca integral para a explicação de tal complexidade. A linguagem, uma das funções superiores cerebrais mais estudadas no homem, por exemplo, traz consigo a dificuldade de se compreender, uniformemente, os processos mentais envolvidos em sua aquisição e reprodução, chegando ao ponto de não se saber ainda quais são esses processos. Os modelos cognitivos de leitura e pronúncia, propostos pela psicologia cognitiva, são apenas hipóteses para tentar demonstrar como tudo isso ocorre, porém, não há consenso entre todos os pesquisadores da área. Por sua vez, a influência da cultura na aquisição e reprodução da linguagem geralmente é estudada com um enfoque antropológico, e, principalmente, com enfoque da psicologia sócio-histórica. A linguagem permite que o homem estruture seu pensamento e ingresse na cultura produzindo transformações no meio, além de continuar se desenvolvendo a partir dos estímulos fornecidos pela sociedade em que se encontra. Porém, pouco se sabe sobre o poder da cultura na modificação de processos biológicas da linguagem.

0 bilinguismo nos demonstra como isso acontece. A criança nasce dentro de uma família que fala a língua $\mathrm{A}$, desenvolvendo sua linguagem conforme os estímulos provenientes da linguagem dos pais. Depois, sua inserção em outra cultura faz com que acabe por se adaptar, desenvolvendo sua capacidade de falar, ler e compreender duas línguas completamente diferentes. E, por ser tema de discussões em diversas áreas da psicologia, a compreensão desses mecanismos da linguagem, no bilinguismo, torna-se fundamental para a identificação e o tratamento de dificuldades encontradas na leitura de crianças em início de fase escolar. Independentemente do método, do objetivo e do interesse (culturais, cognitivos etc.), os processos que fazem parte desse tema sempre estão em voga em pesquisas da psicanálise, psicologia sócio-histórica, psicologia cognitiva, neuropsicologia, linguística, fonoaudiologia, dentre outras. Para Vygotsky, por exemplo, um dos principais teóricos da psicologia sócio-histórica, a princípio a função da linguagem é o intercâmbio social:

É a necessidade de comunicação que impulsiona, inicialmente, o desenvolvimento da linguagem. ... É necessário que sejam utilizados signos, compreensíveis por outras pessoas, que traduzam idéias, sentimentos, vontades, pensamentos de forma bastante precisa. Como cada indivíduo vive sua experiência pessoal de modo muito complexo e particular, o mundo da experiência vivida tem que ser extremamente simplificado e generalizado para poder ser traduzido em signos que possam ser transmitidos aos outros (Oliveira, 1997, p. 42-43).

A aquisição da linguagem tem papel fundamental na constituição da subjetividade humana. Resultado de uma evolução hominídea, que possibilitou a especialização do hemisfério esquerdo cerebral, a linguagem foi seguida da respectiva evolução do ouvido, do desenvolvimento geral do cérebro e de todos os órgãos sensoriais (Engels, 1990). Estudos demonstram que na evolução da espécie humana, o desenvolvimento da linguagem esteve associado à gesticulação, fazendo uso da motricidade, fato que explica a destralidade como dominante, pois, assim como a linguagem, ela também envolve o hemisfério esquerdo do cérebro (De Toni, 2006). 
Causando interesse em vários pesquisadores das neurociências - neuropsicologia, por exemplo -, começa a se desenvolver cientificamente com o estudo dos mecanismos cerebrais da linguagem. De acordo com Luria (1981, p. 6):

A data de nascimento da investigação científica dos distúrbios dos processos mentais pode ser acertadamente tomada como 1861, quando o jovem anatomista francês Paul Broca teve a oportunidade de descrever o cérebro de um paciente, que por muitos anos, tinha estado internado na Salpêtrière com um distúrbio acentuado da fala motora (expressiva), e mostrou que o terço posterior do giro frontal inferior estava destruído no cérebro desse paciente.

Em contrapartida, Carl Wernicke em 1873 descreveu casos de incompreensão da fala audível, a partir de estudos de lesões em outra parte do cérebro: o terço posterior do giro temporal superior esquerdo. Nota-se que essas descobertas localizacionistas enfatizam a questão da especialidade do hemisfério esquerdo no cérebro, até hoje reconhecido como principal responsável pelos mecanismos da linguagem. Isso comprova que a linguagem não só tem papel fundamental na constituição do ser humano, como teve, também, na constituição de um campo de pesquisa específico das neurociências.

Após as pesquisas de Broca e Wernicke, no século XIX, os neurologistas da época demonstraram um intenso interesse pelas localizações de funções mentais em determinadas partes do córtex cerebral. Seguindo a isso, foram encontrados no córtex cerebral um "centro para conceitos" (na região parietal inferior esquerda), um "centro para a escrita" (na parte posterior do giro frontal médio esquerdo), um "centro para cálculos matemáticos", um "centro para leitura" e um "centro para orientação no espaço", necessários para um bom desenvolvimento da linguagem (Luria, 1981).

Apesar das tentativas de localizar processos psicológicos complexos diretamente em lesões circunscritas do cérebro, e de essa ser a ideia dominante no século XIV, pesquisadores da época não deixaram de se contrapor ao movimento que Luria chama de localizacionismo estreito. Hughlings Jackson foi o principal defensor da ideia de que a organização cerebral dos processos mentais complexos deveria ser abordada do ponto de vista do nível de construção de tais processos, em vez de o ser do ponto de vista de sua localização em áreas particulares do cérebro. Assim, a ideia de Jackson, de certa forma, era muito semelhante à de Flourens (séculos XVIII e XIV), que acreditava que as funções cerebrais eram desempenhadas pelo cérebro como um todo. Conforme De Toni, Romanelli e Salvo (2005, p. 50):

H. Jackson enfatizou que o sistema nervoso era subdivido por hierarquia funcional, sendo que cada parte do mesmo correspondia a determinado nível de funcionamento. A partir da medula, passando pelos gânglios basais até o córtex cerebral, cada uma destas camadas corresponderia a um nível evolutivamente superior de atividade cognitiva. ... Salientou, também, que cada uma das funções mentais superiores (como a linguagem) era desempenhada por todo o cérebro, sendo que cada área do mesmo contribuiria, no conjunto, com uma determinada parcela para o ideal funcionamento cognitivo.

Seu trabalho não teve uma boa repercussão na época. Em razão de sua complexidade, somente 50 anos mais tarde alguns neurologistas revitalizaram o trabalho de Jackson. Monakow (1914), Head (1926) e Goldstein $(1927,1944,1948)$ não negaram que funções elementares estariam localizadas em áreas específicas do cérebro, porém afirmaram que 'fenômenos complexos, de 'semântica' ou 'comportamento categórico' são o resultado da atividade de todo o cérebro, em vez de serem produto do funcionamento de áreas locais do córtex cerebral" (Luria, 1981, p. 11).

Tanto o localizacionismo quanto o unitarismo não foram suficientes para dar base científica a outras pesquisas mais elaboradas. Alexander Romanovich Luria (1902-1977), orientado pelos pensamentos de Vygotsky, de que as funções corticais superiores têm três princípios centrais (a- relacionamentos interfuncionais, plásticos e modificáveis; b- sistemas funcionais dinâmicos como resultantes das funções elementares; c- a reflexão da realidade sobre a mente humana) e influenciado pelas pesquisas soviéticas, propõe uma ciência romântica, em consonância com a fisiologia e a neurologia, sem depender integralmente delas e, mais importante, sem nunca perder de vista a perspectiva humanista da compreensão e do entendimento das condições clínicas estudadas (Kristensen, Almeida 
\& Gomes, 2001). Ele também pesquisou a influência da cultura nos processos psicológicos superiores de moradores de vilarejos da Ásia Central. Dentre várias tarefas aplicadas ao grupo de pesquisandos, os resultados apontaram sempre para a mesma direção: mudanças nas formas práticas de atividades produziram alterações qualitativas nos processos de pensamento dos indivíduos estudados (Oliveira, 1997). Em uma visão antropológica, a identidade se constrói na interseção do cultural com o cognitivo, demonstrando justamente o que Luria encontrou em sua pesquisa.

Nas palavras de De Toni, Romanelli e Salvo (2005), para Luria, as funções cognitivas formam sistemas funcionais complexos, que necessitam da ação combinada de todo o córtex cerebral, embora sua base esteja situada em grupos de células dispersas que atuariam conjuntamente. Assim, funções mentais superiores (como raciocínio, planejamento, memória, linguagem etc.) dependeriam do cérebro como um todo, mas com partes distintas do cérebro sendo responsáveis pelos diferentes aspectos do conjunto.

Além disso, Luria (1981) dividiu o cérebro humano em três unidades funcionais: uma unidade funcional para regular o tono ou a vigília, uma unidade para obter, processar e armazenar as informações que chegam do mundo exterior e uma unidade para programar, regular e verificar a atividade mental. $\mathrm{Na}$ unidade receptora, as informações fluem das áreas primárias (sensação) para as secundárias (percepção) e, finalmente, para a área terciária (interpretação), localizada na confluência temporoparietal. Na unidade executora, o fluxo é invertido, indo da área terciária (área pré-frontal) para as áreas secundárias (planos motores) e, por fim, para a área primária motora (motricidade) (Cosenza, 2004).

A partir da superação da crise localizacionista vs. unitarista, o modelo de sistema funcional trouxe consequências diretas para a neuropsicologia. Seu modelo teórico passou a dirigir o trabalho neuropsicológico, pois depois de assumido esse modelo, as investigações entre relação cérebro-comportamento passaram a ser mais rigorosas. Um sistema funcional se caracteriza pela mobilidade/plasticidade de suas partes componentes e, assim, é possível a reestruturação da função perdida, modificando-se os mecanismos relacionados àquela função sem, no entanto, alterar o objetivo final do processo.
Resultado disso é o avanço na compreensão dos processos subjacentes da linguagem. Um maior conhecimento das estruturas cerebrais possibilitou que os pesquisadores passassem a estudar as estruturas ou os microprocessos que envolvem a linguagem como um todo, logo após a passagem das informações mesmas pelos órgãos sensoriais. Por exemplo: para que a leitura em voz alta ocorra (aqui com enfoque da neuropsicologia cognitiva), faz-se necessária uma conexão entre as regiões occipitais (local onde são identificados os grafemas) e a área de Wernicke, que se encontra no lobo temporal esquerdo e permite a compreensão dos símbolos gráficos da escrita. Logo após, a informação é dirigida até a área de Broca (também no lobo temporal esquerdo) para que a pronúncia seja realizada (Romanelli, 2007).

É a partir da década de 1950, nos Estados Unidos, que a psicologia cognitiva começa a se desenvolver, especialmente no que se refere aos estudos sobre processamento da informação, se diferenciando da neuropsicologia no seguinte aspecto: a primeira promove modelos de funcionamento da mente, enquanto a segunda testa a aplicabilidade deles (Kristensen, Almeida \& Gomes, 2001).

Quanto à linguagem, principalmente nas tarefas de ler e escrever, a psicologia cognitiva e a neuropsicologia cognitiva focalizam a análise dos processos neurocognitivos subjacentes às habilidades do leitor/escritor (Salles \& Parente, 2007).

Os psicólogos cognitivos Eysenck e Keane (2007) relacionam os processos de leitura com a identificação e a extração de significado das palavras individuais. Para os autores, outros processos operam no nível da frase ou sentença, e outros ainda se propõem a estudar a organização geral e estrutura temática de uma história ou livro. No nosso caso, as palavras individuais ou isoladas terão enfoque principal de estudo.

É através de modelos de leitura e de escrita da neuropsicologia cognitiva que se busca compreender os processos cognitivos de leitura/escrita em crianças em fase inicial de aprendizagem. São os indícios, que aparecem na utilização do método de análise psicolinguística, que permitem ao pesquisador inferir sobre o processo subjacente ao desempenho nas tarefas de leitura e escrita de palavras. Um exemplo desses indícios são os tipos de erros nas tarefas propostas às crianças, bem como a 
comparação do desempenho entre estímulos (Salles \& Parente, 2007).

Ainda para Salles e Parente (2002), os processos mentais que possibilitam ao leitor identificar, compreender e pronunciar as palavras são denominados de Modelos de Leitura de Dupla Rota. Esse nome se deve à possível utilização de duas rotas cognitivas do processo de informação, ambas começando pelo input visual: a rota lexical e a rota fonológica (sublexical). 0 modelo mais utilizado para descrever o reconhecimento de palavras escritas, segundo Guimarães (2004), é o de Ellis (1995). Para a autora, esse modelo nos traz a ideia de que o reconhecimento de palavras é produto de uma atividade orquestrada, na qual diversos subsistemas trabalham de forma independente, chegando a um mesmo objetivo, que é a pronúncia ou a fala.

Ilustrando esse modelo (Figura 1), é possível afirmar que três rotas podem ser utilizadas para se ler uma palavra isolada em voz alta. Duas rotas exigem da palavra lida uma representação no léxico de input visual e uma rota é usada quando não há representação da palavra no input visual.

Rota $1^{1}$ : chamada de rota lexical, é a de leitura via significado, na qual a representação semântica da palavra lida faz a mediação da leitura (Guimarães, 2004). Ilustrando o diagrama proposto por Ellis (1995), a descrição da rota ficaria da seguinte maneira: palavra escrita $\Rightarrow$ sistema de análise visual $\Rightarrow$ léxico de input visual $\Rightarrow$ sistema semântico $\Rightarrow$ léxico da produção da fala $\Rightarrow$ nível do fonema $\Rightarrow$ fala. Esta

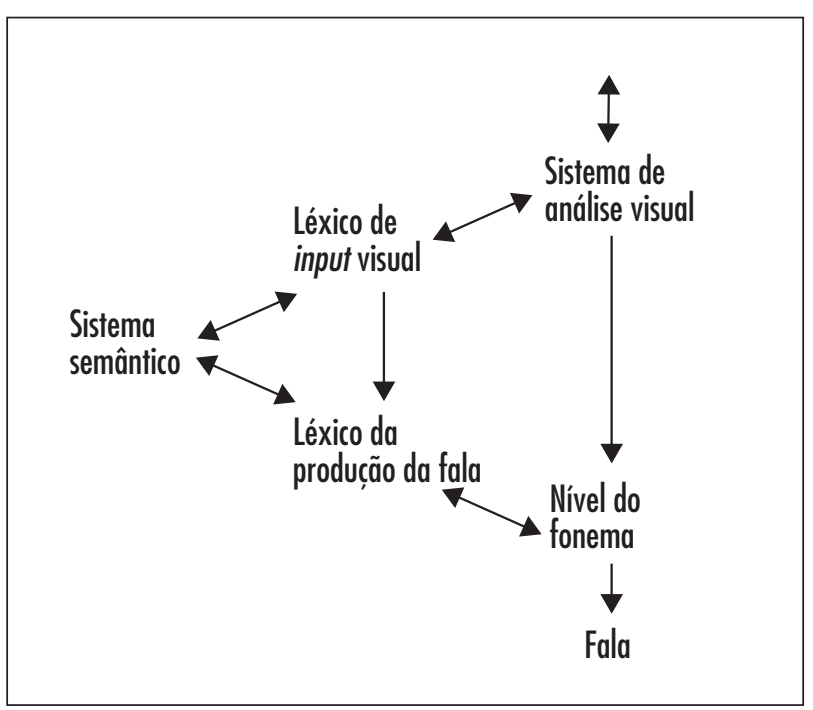

Figura 1 - Modelo de reconhecimento de palavras de Ellis (1995) Fonte: Guimarães, 2004. rota também é conhecida por semântica, onde a leitura da palavra é feita via seu significado armazenado no sistema semântico.

Rota 2: também conhecida por rota lexical, porém não semântica, a leitura por essa rota é realizada a partir de uma conexão direta do léxico de input visual com o léxico de produção da fala (Guimarães, 2004). Essa rota também pode ser chamada de lexical direta, pois a pronúncia da palavra não exige decodificação. Assim, temos: palavra escrita $\Rightarrow$ sistema de análise visual $\Rightarrow$ léxico de input visual $\Rightarrow$ léxico de produção da fala $\Rightarrow$ nível do fonema $\Rightarrow$ fala.

Rota 3: esta rota é utilizada quando o item analisado visualmente não está representado no léxico de input visual e, por consequência, não é reconhecido como palavra. Portanto, nomeia-se esta rota como fonológica ou sublexical, pois a pronúncia é construída por meio da conversão dos segmentos ortográficos em segmentos fonológicos (Guimarães, 2004). Dessa forma, é utilizada a seguinte rota: palavra escrita $\Rightarrow$ sistema de análise visual $\Rightarrow$ nível do fonema $\Rightarrow$ fala.

Fazendo uma análise mais aprofundada das estruturas que compõem o Modelo de Dupla Rota, é possível afirmar que o sistema de análise visual possui duas funções principais: formar representações das letras impressas diferenciando uma letra da outra e codificar a posição de cada letra na palavra. o léxico de input visual tem a responsabilidade de identificar se a cadeia de letras forma uma palavra conhecida ou não. É o léxico de input visual que armazena todas as palavras familiares, porém sem conter seus significados e suas pronúncias. Por sua vez, após a identificação das palavras, o léxico de input visual encaminha informações para o sistema semântico, visto como o depósito de todo o conhecimento acerca dos significados de palavras familiares; mas, ele não armazena o conhecimento de como se pronunciar a palavra que o representa. Este conhecimento sobre pronúncias é o papel do léxico de produção da fala. Por fim, o nível do fonema pode ser considerado um "depósito" de curto prazo, pois armazena temporariamente os fonemas das palavras no intervalo entre sua recuperação do léxico de produção da fala e sua articulação (Guimarães, 2005).

A rota lexical possibilita que palavras de alta frequência (quantidade de ocorrência na língua) sejam reconhecidas mais rapidamente do que palavras de baixa frequência. Esse é um indício de que o leitor está utilizando a rota lexical, o que, segundo Salles e Parente (2002), é conhecido por efeito de 
frequência. Para as autoras, outro indício de leitura pela rota lexical se dá pela presença de um efeito de lexicalidade:

... ou seja, palavras reais sendo identificadas mais rápida e precisamente do que pseudopalavras é outro indício de leitura por rota lexical. As palavras, quando familiares, têm unidades de reconhecimento no léxico de entrada visual, o que não ocorre com as pseudopalavras (Salles \& Parente, 2002, p. 322).

Para Guimarães (2004), a lexicalidade apoia-se na distinção entre pseudopalavras (palavras inventadas) e palavras reais, e como não há representações ortográficas de pseudopalavras no sistema lexical, necessariamente elas são lidas pela rota fonológica (sublexical).

Outras variáveis psicolinguísticas também influenciam na utilização de rota para leitura. Entre outros, Ellis (1995) também cita a regularidade/efeito de regularidade da palavra (correspondência grafia-som) e o comprimento/efeito de extensão (número de letras contidas na palavra) (Guimarães, 2004).

Em respeito ao efeito de regularidade, as palavras regulares podem ser lidas corretamente pela rota fonológica e pela rota lexical. Porém, se a palavra lida tem uma ortografia irregular, a rota sublexical tende a regularizá-la, produzindo uma pronúncia errada (Guimarães, 2004). As palavras regulares possibilitam uma leitura por meio de "conversão grafema-fonema unívoca", enquanto as irregulares possuem relações grafonêmicas ambíguas (Salles \& Parente, 2002).

No que diz respeito ao comprimento, ou efeito de extensão, a leitura pela rota fonológica é mais precisa para itens curtos, e a rota lexical não sofre efeito do comprimento (Guimarães, 2004).

0 uso de rotas de leitura em crianças bilíngues causa interesse justamente porque, de acordo com Hagége (2005), citado por Romanelli (2007), pessoas bilíngues têm maior flexibilidade cognitiva do que pessoas unilíngues. Apesar de haver muita divergência na área acerca de como a aprendizagem de outras línguas acontece neurologicamente, de fato, pode-se afirmar que bilíngues se saem melhor em avaliações de inteligência verbal, raciocínio e resoluções de problemas (Romanelli, 2007). Esse pode ser um forte indício de que o bilinguismo não afeta somente os resultados de execução de tarefas específicas, mas também o trajeto cognitivo de leitura cerebral.

Para Capovilla, A., Machalous e Capovilla, C. (2003), o uso preferencial de rotas cognitivas de leitura pode ser influenciado diretamente por características específicas da ortografia (ex.: grau de irregularidade grafofonêmica), pois elas afetam a eficácia relativa de diferentes estratégias. Ainda segundo os autores, a ortografia alemã concentra-se no extremo da regularidade com correspondências entre fonemas e grafemas biunívocas, e quase nenhuma irregularidade. Por sua vez, a língua inglesa é o oposto, com variações entre grafemas e fonemas que afetam o desempenho na leitura e a escrita, tendo um grau de correspondência grafofonêmica extremamente irregular. Já a língua portuguesa encontra-se entre uma e outra.

De acordo com os resultados encontrados no estudo de Capovilla, A. et al. (2003), com crianças bilíngues (falantes do alemão e português), crianças falantes somente do português e crianças falantes somente do alemão, é possível afirmar que em português a leitura é feita de modo claramente mais global ou ideovisual do que no alemão, ou seja, a partir da utilização da rota lexical de leitura, o que pode levar a erros com itens visualmente semelhantes. Já a ortografia alemã leva a uma leitura mais fonológica (pronúncia da palavra construída por meio da leitura de segmento por segmento, através da utilização de regras de correspondência grafofonêmicas) do que a portuguesa, fazendo com que pseudopalavras passem despercebidas e soem como palavras reais e corretas.

Dessa maneira, este trabalho visa verificar qual a rota cognitiva preferencialmente utilizada, na leitura de palavras isoladas, em crianças bilíngues (falantes de alemão/português e falantes de inglês/português) do $3^{\circ}$, $4^{\circ}$ e $5^{\circ}$ anos do Ensino Fundamental, além de fazer uma análise comparativa dos resultados entre bilíngues e falantes somente da língua portuguesa.

Além disso, os possíveis resultados fomentarão ainda mais os estudos acerca da influência da cultura na constituição do indivíduo e, principalmente, sobre a influência dos diferentes tipos de metodologia de ensino de leitura na iniciação escolar, abrindo caminhos para pesquisadores e descobertas relacionadas ao tema. 


\section{Método}

O estudo contou com a participação de 34 crianças falantes somente do português (grupo nomeado de grupo controle), onde 24 crianças são do sexo feminino e dez do sexo masculino, e outro grupo de 30 crianças bilíngues, onde 20 crianças são falantes do português e alemão (sete crianças são do sexo masculino, e 13 do sexo feminino) e dez crianças falantes de inglês e português (cinco do sexo masculino e cinco do sexo feminino). A amostra total foi de 64 crianças. Os colégios onde foi conduzida a pesquisa são de natureza particular, sendo que um caracteriza-se pelo cunho confessional de valorização da cultura e língua alemã, trazidas por seus fundadores, enquanto o outro tem como principal objetivo a valorização da experiência multicultural. Os alunos bilíngues (em ambos os colégios) passam por vários níveis de aprimoramento da língua à formação integral no Ensino Fundamental e Médio. A média de idade dos participantes do estudo foi de 8 anos e 4 meses, com desvio padrão de 0,86. Os participantes foram eleitos por conveniência, sendo convidados todos os alunos do $3^{\circ}$, $4^{\circ}$ e e $5^{\circ}$ anos, adotando-se aqueles cujos pais concordaram com o termo de consentimento livre e esclarecido e que voluntariamente se dispuseram a participar da pesquisa, tomando o cuidado de o grupo controle ter características muito semelhantes de idade, escolaridade e desempenho escolar em relação ao grupo bilíngue.

Para a leitura de palavras isoladas, foi utilizado o instrumento construído por Salles (2001) e Salles e Parente (2002). 0 instrumento consiste numa lista de 60 estímulos, divididos em três categorias de 20 palavras cada: palavras regulares, irregulares e pseudopalavras. Além de permitir a avaliação da precisão na leitura oral de palavras, o instrumento possibilita uma análise das estratégias de leitura dos alunos, permitindo que se descubra qual a rota de leitura preferencialmente utilizada, segundo modelo de leitura de dupla-rota de Ellis (Salles, 2005). Os estímulos foram apresentados conforme a ordem disposta no instrumento, por meio do software Microsoft PowerPoint, escrito originalmente para o sistema operacional Microsoft Windows.

0 projeto de pesquisa foi enviado à direção dos colégios com a finalidade de conseguir liberação para aplicação dos testes. Os pais também foram informados dos objetivos da pesquisa e assinaram um termo de consentimento informado autorizando a participação de seu(s) filho(s). Após a liberação dos pais e a disponibilidade dos colégios para a pesquisa, a aplicação do teste foi feita individualmente, em sala separada, contando apenas com a presença do examinador, da criança e de um representante da escola. 0 examinador apresentou as palavras às crianças pelo computador, sem tempo predeterminado para obtenção de respostas, que foram gravadas, a fim de facilitar a transcrição para a análise dos resultados.

\section{Análise e discussão dos resultados}

De acordo com os resultados, não houve diferença no desempenho geral das crianças (acertos e erros) quando comparadas entre os gêneros, sexo masculino e feminino. Essa indicação está baseada nos valores oferecidos pelo teste Mann-Whitney (Wilcoxon Rank-Sum Test): $\mathrm{U}=443,5$ e $\mathrm{p}=0,794$.

Quando se levou em conta a diferença de idades durante o processo, notamos que o salto qualitativo que possibilitou um destaque em relação às idades anteriores se deu aos 10 anos. As crianças foram subdividas por idades e o resultado de seus desempenhos foram comparados entre si; as crianças de 10 anos tiveram um desempenho melhor e estatisticamente significativo na leitura das palavras isoladas em relação às demais, de 7, 8 e 9 anos. 0 Gráfico 1 apresenta esses achados de forma precisa.

Os valores de $U$ e $p$ também reafirmam o disposto no gráfico. Enquanto não houve diferença significativa $(p<0,05)$ de desempenho entre as crianças de 7, 8 e 9 anos, os valores de p e U acentuaram-se quando o desempenho das crianças de 10 anos foi comparado com o desempenho de crianças com 7 $\operatorname{anos}(\mathrm{U}=3,5$ e $\mathrm{p}=0,0021)$ e 8 anos $(\mathrm{U}=32,5$ e $\mathrm{p}=$ $0,003)$. Por sua vez, o desempenho das crianças de 9 anos não teve diferença estatisticamente significativa com o desempenho das crianças de 10 anos; mas, diferentemente delas, não apresentou tais diferenças quando comparados com o desempenho das crianças com idades de 7 e 8 anos também. Isso pode ser um efeito significativo da influência da série escolar sobre os escores de leitura, visto que todas com 10 anos frequentavam o $5^{\underline{0}}$ ano (4 $4^{\underline{a}}$ série) do Ensino Fundamental, enquanto as demais frequentavam séries anteriores. 
O Quadro 1 demonstra como ficou a distribuição da porcentagem com relação às estratégias de leitura (utilização de rotas) pelas crianças bilíngues alemãs, bilíngues inglesas e integrantes do grupo controle (falantes somente da língua portuguesa). A utilização preferencial de uma rota não exclui a possibilidade de que a criança utilize outras estratégias de leitura simultaneamente.

O Quadro 1 indica que os bilíngues falantes da língua portuguesa e inglesa utilizam preferencialmente a rota fonológica de leitura (40\%), enquanto outros 30\% desse mesmo grupo utilizam preferencialmente ambas as rotas. Como a ortografia inglesa encontra-se no extremo da regularidade (Capovilla, A. et al., 2003), supõe-se que a leitura de palavras isoladas, por crianças bilíngues inglesas, seja feita por ambas as rotas por estas estarem expostas a estímulos com relações grafonêmicas razoavelmente

Gráfico 1 - Porcentagem de acerto na leitura de palavras isoladas das crianças, distribuídas por idade

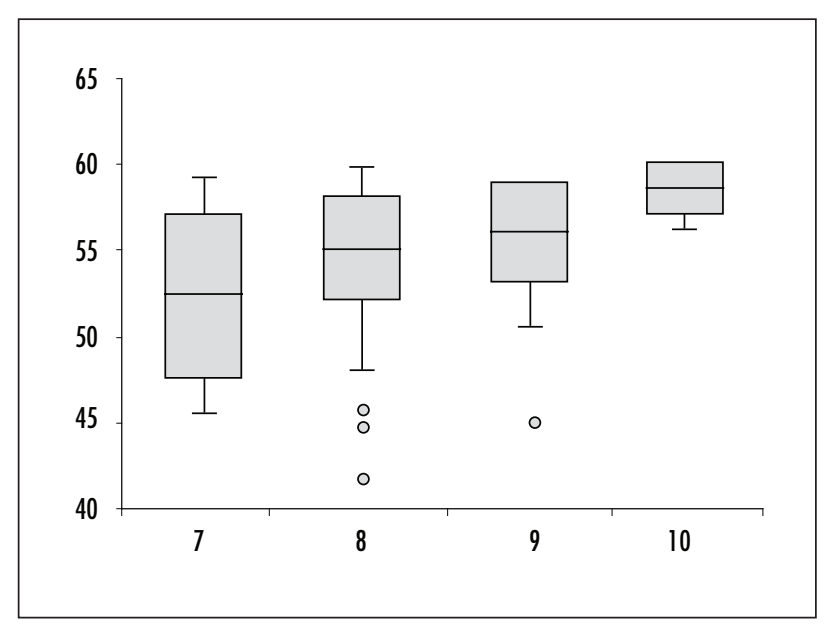

Fonte: Dados da pesquisa. regulares, regras de posição, e algumas irregularidades bem conhecidas (Lemle, 1991, citado por Capovilla, A. et al., 2003), características básicas da língua portuguesa.

De forma semelhante, bilíngues falantes da língua portuguesa e alemã tiveram uma preferência de utilização de ambas as rotas (65\%). Conforme Capovilla, A. et al. (2003), a leitura da ortografia portuguesa tende a ser ideovisual ou global enquanto que a ortografia alemã tende a ser lida por uma rota fonológica. Por isso, é possível pensar que a criança inserida em um ambiente em que a exposição aos dois tipos de línguas é frequente (alemã e portuguesa) desenvolve habilidade de leitura por ambas as rotas, o que é corroborado pelos resultados encontrados.

Desconsiderando o país de origem das crianças, as características particulares de cada língua e baseando-se apenas no critério de que são bilíngues, falantes da língua portuguesa e alemã ou inglesa, a distribuição de porcentagem na utilização das rotas, comparada à utilização de rotas pelo grupo controle, pode ser visualizada no Quadro 2.

0 teste Mann-Whitney demonstra que, embora a distribuição de porcentagem referente à utilização de rotas entre as crianças bilíngues e o grupo controle tenha sido heterogênea, não houve diferença significativa entre os mesmos grupos quando se levou em consideração o desempenho de leitura geral das crianças, sem análise das rotas utilizadas ( $\mathrm{U}=501 ; \mathrm{p}=0,18)$. 0 Quadro 2 novamente traz um indicativo de preferência pela utilização da rota lexical entre o grupo controle (50\%), ao passo que os bilíngues fazem uso preferencial de ambas as rotas (53,33\%). Conforme Salles (2005), há interação entre os processos lexicais e fonológicos de leitura que seguem os modelos de leitura e escrita

Quadro 1 - Distribuição de porcentagem na utilização de rotas cognitivas de leituras em crianças

\begin{tabular}{cccccccccccc}
\hline & PL & PF & MA & PL e PF & BA e PL & BA e PF & $\begin{array}{c}\text { BA, PL e } \\
\text { PF }\end{array}$ & MA e PL & $\begin{array}{c}\text { MA e PF } \\
\text { MA, PL e } \\
\text { PF }\end{array}$ \\
\hline ALE & 20 & 5 & 0 & 65 & 0 & 0 & 0 & 0 & 5 & 5 \\
ING & 10 & 40 & 0 & 30 & 0 & 0 & 0 & 10 & 0 & 10 \\
POR & 50 & 2,94 & 0 & 8,82 & 17,6 & 5,88 & 14,7 & 0 & 0 & 0 \\
\hline
\end{tabular}

Legenda: ALE = crianças bilíngues da língua alemã e portuguesa; $I N G$ = bilíngues da língua inglesa e portuguesa; POR = grupo controle, falantes apenas da língua portuguesa; $\mathrm{PL}=$ preferencialmente lexical; $\mathrm{PF}=$ preferencialmente fonológica; $\mathrm{MA}=$ maus leitores por ambas as rotas; $\mathrm{BA}=$ bons leitores por ambas as rotas.

Fonte: Dados da pesquisa. 
de dupla-rota; sendo assim, embora verifique-se a predominância pela utilização da rota lexical no grupo controle, não se pode excluir a possibilidade de ambas as rotas atuarem juntas.

Em seu estudo com crianças da $2^{\underline{a}}$ série do Ensino Fundamental de escolas públicas do Rio Grande do Sul, Salles (2005) constatou predomínio da rota fonológica sobre a lexical na leitura e escrita de palavras isoladas. Porém, conforme Marturano (1999), citado por Salles (2005), fatores familiares, nível socioeconômico e educacional dos pais e recursos no ambiente físico afetam diretamente o processo de aprendizagem da criança na escola. Considerando que famílias de nível socioeconômico baixo tendem a ler menos para seus filhos (Pennington, 1997, citado por Salles, 2005), e que a amostra deste estudo é estritamente de crianças com nível socioeconômico alto (escolas particulares), infere-se que a preferência pela utilização de rota lexical do grupo controle é resultado da estimulação recebida dos pais e da escola, com propostas pedagógicas bem definidas, métodos e qualidade de ensino.

Ainda referindo-se à comparação entre grupo controle e grupo de bilíngues (sem diferenciação de língua inglesa e alemã), percebe-se que não houve efeito de extensão na leitura de palavras isoladas em ambos os grupos, enquanto que efeitos de lexicalidade, regularidade e frequência estiveram presentes e a diferença da intensidade deles nos dois grupos teve significância estatística, com o valor de p inferior a 0,05 (Quadro 3).

Para Salles e Parente (2007), o uso de rota lexical pode ser inferido a partir dos efeitos de frequência e lexicalidade. No grupo bilíngue, o efeito de frequência foi maior, sugerindo que esse valor é resultado da exposição simultânea às palavras em língua portuguesa e alemã/inglesa. Em contrapartida, o efeito de frequência no grupo controle foi menor, sugerindo que esse fator pode estar relacionado à ideia de que palavras de alta frequência tendem a ser lidas/ escritas mais rapidamente do que palavras de baixa frequência, por já estarem acessíveis no léxico mental. Essa acessibilidade é consequência de os alunos do grupo controle, por prática e rotina, terem mais contato com palavras em língua portuguesa do que os bilíngues, além do fato de que a lista de estímulo é composta somente por pseudopalavras e palavras da língua portuguesa.

Quadro 2 - Distribuição de porcentagem na utilização de rotas cognitivas de leituras em crianças bilíngues

\begin{tabular}{cccccccccc}
\hline & PL & PF & PL e PF & BA e PL & BA e PF & $\begin{array}{c}\text { BA, PL e } \\
\text { PF }\end{array}$ & MA e PL & MA e PF & $\begin{array}{c}\text { MA, PL e } \\
\text { PF }\end{array}$ \\
\hline POR & 50 & 2,94 & 8,82 & 17,6 & 5,88 & 14,7 & 0 & 0 & 0 \\
BIL & 16,66 & 16,66 & 53,33 & 0 & 0 & 0 & 3,33 & 3,33 & 6,66 \\
\hline
\end{tabular}

Legenda: BIL = sem diferenciação de línguas; POR = grupo controle, falantes apenas da língua portuguesa. $\mathrm{PL}=$ preferencialmente lexical; $\mathrm{PF}$ = preferencialmente fonológica; $\mathrm{MA}=$ maus leitores por ambas as rotas; $\mathrm{BA}=$ bons leitores por ambas as rotas. Fonte: Dados da pesquisa.

Quadro 3 - Intensidade dos efeitos de frequência, extensão, regularidade e lexicalidade na leitura de palavras isoladas do grupo controle

\begin{tabular}{|c|c|c|c|c|c|c|}
\hline Efeitos & Grupos & Média & DP & Mínimo & Máximo & $\mathbf{p}$ \\
\hline \multirow{2}{*}{ Frequência } & Controle & 0,08 & 0,06 & 0 & 0,28 & \multirow{2}{*}{$<0,0001$} \\
\hline & Bilíngues & 0,30 & 0,06 & 0,2 & 0,43 & \\
\hline \multirow{2}{*}{ Extensão } & Controle & $-0,03$ & 0,06 & $-0,2$ & 0,1 & \multirow{2}{*}{$>0,005$} \\
\hline & Bilíngues & $-0,02$ & 0,06 & $-0,1$ & 0,17 & \\
\hline \multirow{2}{*}{ Regularidade } & Controle & 0,05 & 0,07 & $-0,05$ & 0,3 & \multirow{2}{*}{$<0,0001$} \\
\hline & Bilíngues & 0,12 & 0,09 & 0 & 0,4 & \\
\hline \multirow{2}{*}{ Lexicalidade } & Controle & 0,09 & 0,09 & $-0,18$ & 0,25 & \multirow{2}{*}{$<0,0001$} \\
\hline & Bilíngues & 0,05 & 0,09 & $-0,13$ & 0,3 & \\
\hline
\end{tabular}

Fonte: Dados da pesquisa. 
Por sua vez, o efeito de lexicalidade consiste no fato de palavras reais serem lidas com mais precisão do que as pseudopalavras (Salles \& Parente, 2007). 0 grupo controle teve um efeito de lexicalidade superior ao grupo bilíngue, confirmando a preferência pela rota lexical descrita no Quadro 2. Esse é um indício de que o grupo controle tende a mais lexicalizações, ou seja, conforme Ellis (1995), ele ativa uma unidade de reconhecimento de uma palavra real, ortograficamente semelhante às pseudopalavras no léxico de input visual (Salles \& Parente, 2007), por ter mais palavras reais em língua portuguesa disponíveis em seu repertório lexical do que os bilíngues, que ora leem em alemão/inglês, ora em português. $\mathrm{O}$ uso da rota fonológica pode ser inferido a partir dos efeitos de extensão e regularidade. Ambos os grupos (bilíngues e controle) não foram afetados em seu desempenho de leitura pela quantidade de letras das palavras, sugerindo que esta não foi feita de modo tão lento e gradual quanto se esperava, sobretudo no grupo bilíngue. 0 efeito de regularidade, contudo, foi mais intenso no grupo bilíngue, supondo que as palavras irregulares, nesse grupo, foram 'regularizadas' e automaticamente lidas de forma mais incorreta do que se tivessem a pronúncia gerada pela rota lexical (Salles \& Parente, 2007). Por fim, isso indica que o efeito de regularidade foi superior no grupo bilíngue justamente por as línguas alemã e inglesa serem o oposto uma da outra no que tange às correspondências grafema-fonema, estando a primeira no extremo da regularidade, e a segunda, no extremo da irregularidade.

Mesmo assim, o efeito de regularidade foi praticamente o mesmo no grupo bilíngue alemão e no grupo bilíngue inglês, quando apenas comparados entre si: 0,13 no primeiro e 0,12 no segundo, mas não o bastante para ter significância estatística: $\mathrm{p}=202$.

\section{Considerações finais}

Conclui-se que tanto o objetivo geral quanto os objetivos específicos do estudo foram alcançados. A análise dos resultados mostrou que falantes da língua portuguesa do $3^{\circ}$, $4^{\circ}$ e e $5^{\circ}$ anos do Ensino Fundamental tendem a ler preferencialmente palavras isoladas pela rota lexical, enquanto os bilíngues utilizam ambas as rotas.

Tanto o grupo controle como o grupo bilíngue foram afetados pelos efeitos de lexicalidade, frequência e regularidade. Contudo, não houve efeito de extensão nos grupos, sendo o efeito de lexicalidade o mais intenso no grupo bilíngue, e os efeitos de regularidade e frequência, os mais intensos no grupo controle.

Em relação ao desempenho geral na leitura (acertos e erros), o salto qualitativo foi aos 10 anos de idade, com desempenho superior e estatisticamente significativo em relação aos demais.

De qualquer forma, as diferenças encontradas neste estudo podem estar relacionadas não somente à influência de outra língua sobre a língua materna, mas também a métodos de ensino diferenciados para bilíngues e falantes somente da língua portuguesa. Reiteramos, ainda, que novas pesquisas devem ser conduzidas a fim de esclarecer esses métodos, reforçar ou refutar tais hipóteses.

\section{Referências}

Capovilla, A. G. S., Machalous, N., \& Capovilla, F. C. (2003). Leitura em crianças bilíngues: Uso das rotas fonológica e lexical em português e alemão. In M. R. Maluf. (Org.). Metalinguagem e aquisição da escrita: Contribuições da pesquisa para a prática da alfabetização. São Paulo: Casa do Psicólogo.

Cosenza, R. (2004). Bases estruturais do sistema nervoso. In V. M. Andrade \& F. H. Santos. Neuropsicologia hoje. São Paulo: Artes Médicas.

De Toni, P. M., Romanelli, E. J., Salvo, C. G. (2005). A evolução da neuropsicologia: Da antiguidade aos tempos modernos. Revista Psicologia Argumento, 23(41), 47-55.

De Toni, P. M. (2006). Bateria Piaget-Head de orientação direita-esquerda: Manual. São Paulo: Vetor.

Engels, F. (1990). O papel do trabalho na transformação do macaco em homem. (4a. ed.). São Paulo: Global Editora.

Eysenck, M. W., Keane, M. T. (2007). Manual de Psicologia Cognitiva. (5a. ed.). Porto Alegre: Artmed.

Guimarães, S. R. K. (2004). Dislexias adquiridas como referência para a análise das dificuldades de aprendizagem da leitura. Educar em Revista, 23(1), 285-306. 
Guimarães, S. R. K. (2005). Aprendizagem da leitura e da escrita: O papel das habilidades metalinguísticas. São Paulo: Vetor.

Kristensen, C. H., Almeida, R. M. M., Gomes, W. B. (2001). Desenvolvimento histórico e fundamentos metodológicos da neuropsicologia cognitiva. Psicologia: Reflexão e Crítica, 14(2), 259-274.

Luria, A. R. (1986). Pensamento e Linguagem: As últimas conferências de Luria. Porto Alegre: Artes Médicas.

Oliveira, M. K. (1997). Vygotsky: Aprendizado e desenvolvimento: Um processo sócio-histórico. São Paulo: Scipione.

Romanelli, B. M. B. (2007). Desempenho na escrita do português de crianças bilíngues cuja língua materna é o francês. Dissertação de Mestrado, Universidade Federal do Paraná, Curitiba.
Salles, J. F., Parente, M. A. M. P. (2002). Processos cognitivos na leitura de palavras em crianças: Relações com compreensão e tempo de leitura. Psicologia: Reflexão e Crítica, 15(2), 321-331. doi:10.1590/ S0102-79722002000200010.

Salles, J. F. (2005). Habilidades e dificuldades de leitura e escritas em crianças de 2a série: Abordagem neuropsicológica cognitiva. Tese de Doutorado, Universidade Federal do Rio Grande do Sul, Porto Alegre.

Salles, J. F., Parente, M. A. M. P. (2007). Avaliação da leitura e escrita de palavras em crianças de $2^{\mathrm{a}}$ série: Abordagem neuropsicológica cognitiva. Psicologia: Reflexão e Crítica, 20(2), 220-228. doi:10.1590/ S0102-79722007000200007. 